\title{
RESEARCH \\ Evaluation by digital subtraction radiography of induced changes in the bone density of the female rat mandible
}

\author{
CRW Mahl and V Fontanella* \\ Universidade Federal do Rio Grande do Sul, Porto Alegre, Brazil
}

Objectives: To verify whether changes in bone mass induced by glucocorticoid and bisphosphonate can be detected by digital subtraction radiography of lateral X-rays in female rat mandibles.

Methods: 36 Rattus norvegicus (Wistar) females were randomly allocated to three groups: Group 1, control $(n=12)$; Group 2, induced osteopaenia $(n=12)$; and Group 3, induced osteopaenia plus risedronate $(n=12)$. Group 1 received subcutaneous saline solution $\left(2 \mathrm{ml} \mathrm{kg}{ }^{-1}\right)$ injections for 12 weeks. Group 2 received $1 \mathrm{mg} \mathrm{kg}^{-1}$ methylprednisolone acetate for 12 weeks. Group 3 received the same treatment as Group 2, plus $3 \mathrm{mg} \mathrm{kg}^{-1}$ risedronate sodium for a further 12 weeks. A radiograph of the left mandible was taken on day 0 and after 12 weeks. A third radiograph was taken in Group 3 after risedronate treatment. Digital subtraction of the radiographs was used to compare the intensity of pixels in the control area and the test area. The animals were killed and the same area assessed by subtraction was histologically evaluated.

Results: ANOVA revealed statistically significant histological differences between the three groups. Tukey's multiple comparisons test showed that Group 2 had the smallest mean proportion of bone trabeculae per field and Group 3 the largest $(\mathrm{F}=37.56 ; P<0.01)$. Radiographic subtraction revealed a higher mean pixel intensity in Groups 1 and 3 vs Group 2. In Group 3, glucocorticoid caused a significant loss in radiographic density, and risedronate restored that loss (Friedman's non-parametric test).

Conclusions: Subtraction radiography was able to detect changes in bone mass induced by glucocorticoid and bisphosphonate.

Dentomaxillofacial Radiology (2008) 37, 438-444. doi: 10.1259/dmfr/58263510

Keywords: bisphosphonates; glucocorticoids; subtraction technique; osteoporosis

\section{Introduction}

Loss of bone mass is prevalent among elderly populations and frequently results in fractures, impacting negatively on this population's quality of life, with enormous socioeconomic repercussions. Its incidence has increased worldwide as a result of the global population's increased longevity. ${ }^{1} \mathrm{~A}$ possible relationship between mandibular bone loss and osteoporosis was originally investigated due to the importance of bone integrity to the success of dental treatment, and it was demonstrated that osteopaenia in humans has oral manifestations. ${ }^{2}$

*Correspondence to: Dr Vania Fontanella, Rua Coronel Paulino Teixeira, 169/ 403, 90420-160 Porto Alegre, RS, Brazil; E-mail: vaniafontanella@ terra.com.br

Received 6 September 2007; revised 8 December 2007; accepted 11 December 2007
Experimental studies of osteoporosis frequently use rodents, due to the fact that they are of low cost and easy to handle, in addition to fitting with current bioethical precepts. ${ }^{3}$ Glucocorticoids, used for prolonged periods, are the pharmacological agents most frequently linked with inducing osteoporosis, since they reduce osteoblast activity without a compensating reduction in bone reabsorption. ${ }^{4}$ In contrast, bisphosphonates are pyrophosphates that inhibit osteoclast production or activity and are considered effective both for the prevention and treatment of glucocorticoidinduced osteoporosis, with the capacity to increase bone mass of the vertebrae and femur. ${ }^{5}$ The most recent animal studies have primarily assessed quantity and quality of bone tissues by means of bone densitometry and microcomputed tomography. ${ }^{5-10}$ While these 
methods are effective, they are less readily available than conventional radiography. Furthermore, their use in experimental research with animal models requires special installations and involves high operational costs.

If mandibular bone loss is related to systemic loss, the possibility of carrying out longitudinal studies with animals in which these changes are quantified by means of radiographic subtraction techniques may open new horizons in osteoporosis research. Therefore, the objective of this study was to investigate whether glucocorticoid- and bisphosphonate-induced changes in bone mass can be detected by means of subtraction radiography of lateral X-rays of female rat mandibles.

\section{Materials and methods}

\section{Study design and sample}

This randomized, controlled animal experiment was approved by the Research Ethics Committee at the School of Dentistry, Universidade Federal do Rio Grande do Sul (Brazil).

36 females of the species Rattus norvegicus, Wistar line, were allocated at random to one of three groups at 13 weeks old, identified by colours on their tails and kept in an environment with a controlled temperature of $23 \pm 3{ }^{\circ} \mathrm{C}$, relative air humidity of $55 \pm 15 \%$ and a light-dark cycle of $12-12 \mathrm{~h}$. They were fed with a standard laboratory diet (Labina ; Purina, Canoas, RS, Brazil), containing $1.3 \%$ calcium, plus water ad libitum.

\section{Experimental groups}

The three groups were as follows: Group 1, control $(n=12)$; Group 2, induced osteopaenia $(n=12)$; and Group 3, induced osteopaenia plus risedronate $(n=12)$. All three groups were treated for 12 weeks; Group 1 was given subcutaneous saline solution $\left(2 \mathrm{ml} \mathrm{kg}^{-1}\right)$ injections three times a week. Group 2 was given methylprednisolone acetate $\left(1 \mathrm{ml} \mathrm{kg}^{-1}\right.$, Depo-Medrol; Pfizer, Puurs, Belgium) in suspension, diluted in saline solution. Group 3 (induced osteopaenia plus risedronate) was given additional treatment with risedronate sodium (3 mg kg${ }^{-1}$, Actonel OSG; Norwich Pharmaceuticals, North Norwich, NY) diluted in distilled water at a volume of $5 \mathrm{ml} \mathrm{kg}^{-1}$ for 12 weeks, six times per week, administered orally with a gavage syringe and needle for rats IC 810 (Insight Equipamentos Científicos Ltda., Ribeirão Preto, São Paulo, Brazil). All animals were weighed at the start and end of the experiment.

\section{Radiographs}

A radiograph was taken of the left mandible of each animal on day 0 and after the initial 12 weeks of treatment. A third radiograph was taken of each animal in Group 3 after the 12 additional weeks of treatment with risedronate.

Radiographs were taken with the animals secured in a positioning device developed by the authors, ${ }^{11}$ in which the rat, under intraperitoneal anesthaesia (sodium thiopental, Thiopentax, $40 \mathrm{mg} \mathrm{kg}^{-1}$; Cristália, São Paulo, Brazil), was held in ventral decubitus on a supporting base with its head positioned and fixed to the cephalostat at three points: the interdental space between the lower and upper central incisors (in occlusion), and the left and right auditory canals. The medial sagittal plane of the head was parallel to the film support and the X-ray machine's cylinder was fitted to the positioning device's locator in such a way as to obtain a vertical angle of $-30^{\circ}$ and a focal distance of $30 \mathrm{~cm}$ (Figure 1).

According to previously established criteria, ${ }^{12}$ the Xray unit operated at $8 \mathrm{~mA}$ at $50 \mathrm{kVp}$ (Dabi Atlante, Ribeirão Preto, Brazil), with a number 2 periapical film, sensitivity E (Ektaspeed Plus; Eastman Kodak Co., Rochester, NY) and exposure time of $1 \mathrm{~s}$.

Films were processed using new solutions in a standardized manner, using the temperature-time method, and images were also digitized in a standardized manner, using a scanner with a transparency adapter (Epson Perfection $2450^{\circledR}$; Epson, Long Beach, CA), at full size, with automatic brightness and contrast adjustment, at a resolution of $300 \mathrm{dpi}$, in 8-bit mode and then saved in TIFF format.

\section{Radiographic subtraction}

Prior to subtraction and due to the animals' growth, it was necessary to perform geometric adjustment of the images using the Regeemy program (image registration and mosaicking, v0.2.43; Instituto National de Pesquisas Espaciais, São José dos Campos, Brazil). The two images to be corrected were displayed side by side, with the first image being the most recent.

Next, corresponding points were marked on both images. Six pairs of reference points were used, demarcating the dimensions of the mandible. Only the first image was resized, based on the points marked, to achieve a similar size to the second image to allow for correct superimposition of the pair of images for subtraction.

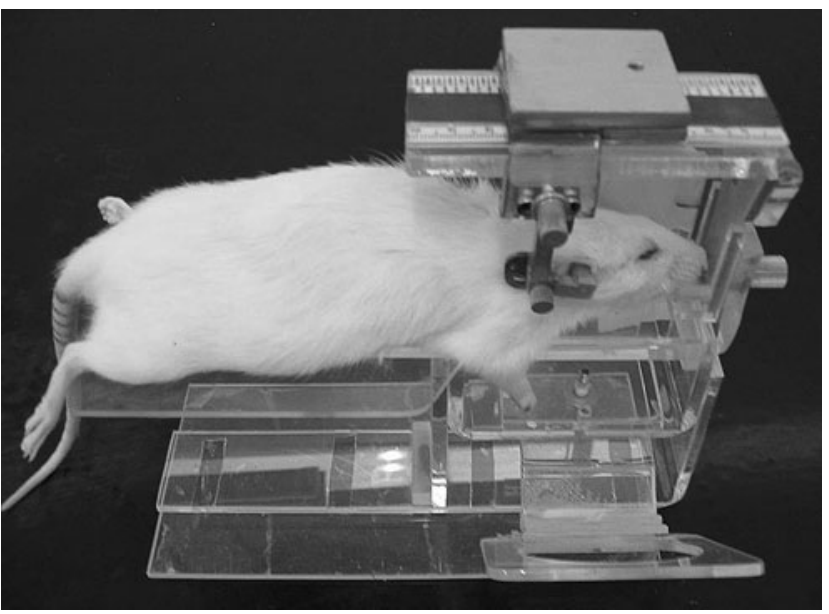

Figure 1 Animal (Rattus norvegicus) in positioning device for radiograph 


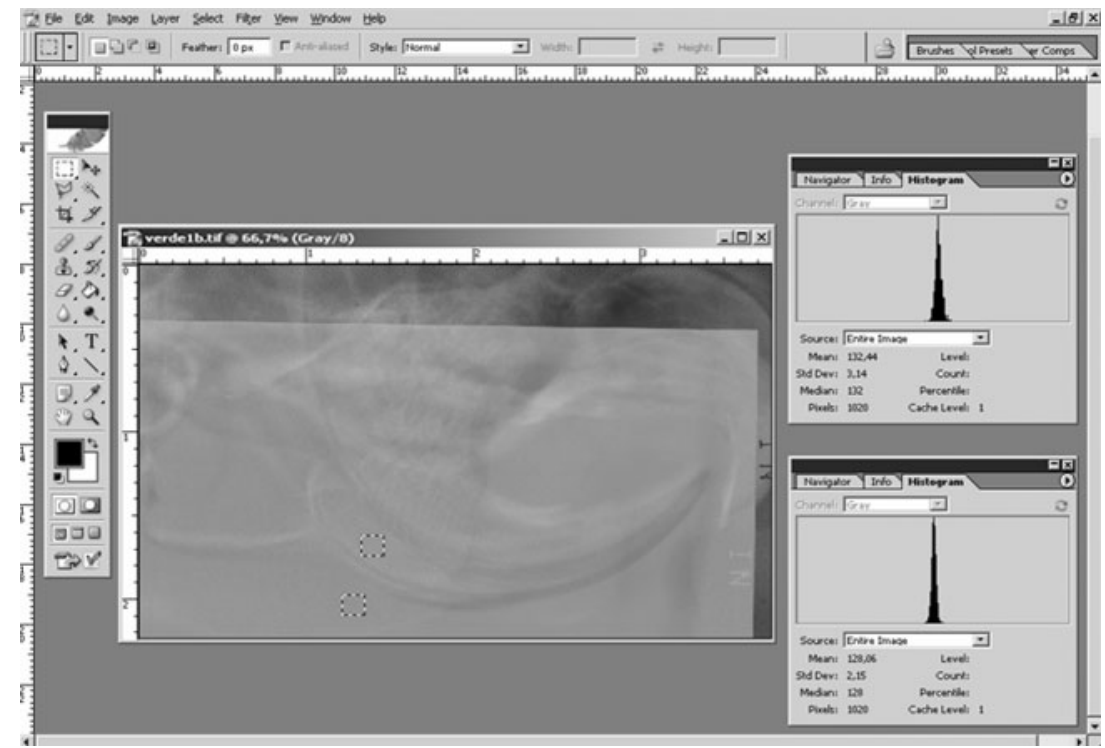

Figure 2 Subtraction image during production of the histogram of selected areas

Radiographic subtraction was carried out using Adobe Photoshop CS (v8.0; Adobe Systems Inc., San Jose, CA). The initial image was pasted over the final image as a new layer, and had its greyscale inverted and its opacity adjusted to $50 \%$. Using the histogram function of the same software, mean and standard deviations were obtained for two areas of each subtracted image: one for the mandible (the same region that would later be assessed histologically, below the second molar apex) and another for the control area, both 1020 pixels (Figure 2). This analysis was performed by a calibrated observer who was blind to which group each image belonged.

In the control and corticoid groups, just one subtraction was performed for each animal (initial $v s$ final radiographs). In the risedronate group, three subtractions per animal were performed: initial vs end of corticoid; end of corticoid $v s$ end of risedronate; and initial $v s$ end of risedronate radiographs.

\section{Euthanizing procedure}

The animals were euthanized under intraperitoneal anaesthesia with sodium thiopental (Thiopentax, $40 \mathrm{mg} \mathrm{kg}^{-1}$; Cristália, São Paulo, Brazil), with those in Groups 1 and 2 killed after 12 weeks and those in Group 3 after 24 weeks of treatment. Once euthanized, the left hemimandible was dissected in order to obtain the same area of interest that had been demarcated on the radiographs. The anatomical samples obtained were stored individually in labelled plastic pots, containing $20 \mathrm{ml}$ of neutral buffered formalin solution at $10 \%$ (Merck, Rio de Janeiro, Brazil).

\section{Preparation and histological assessment of specimens}

The samples were decalcified in a 1:1 solution of formic acid at 50\% (Merck, Rio de Janeiro, Brazil) and sodium citrate at 20\% (Synth Lab, São Paulo, Brazil) at the Oral Pathology Laboratory at the UFRGS Dental School. They were kept submersed in the solution, which was renewed daily, throughout the period of decalcification. The decalcification time was controlled by attempting to transfix the specimen with a histological needle.

The decalcified specimens were cut with a scalpel along the mesial crowns of the second molars and the distal of the third molars and the pieces processed for embedding in paraffin. Semiserial sections were cut perpendicular to the buccal and lingual cortices with a $4 \mu \mathrm{m}$ thickness at $1 \mathrm{~mm}$ intervals, starting at the mesial extreme of the piece, using a Leica RM 2155 rotary microtome (Leica Microsystems, Nussloch, Germany). The sections were mounted on histological slides.

The slides were then stained using haematoxylin and eosin (Harris haematoxylin and Yellow eosin at 3\%; Newprov, Pinhais, Brazil) for viewing under a transmitted light microscope. The central area of each histological section was selected and captured using an optical microscope (Zeiss, Jena, Germany), at a magnification of $\times 4$, coupled to a digital camera (Nikon Coolpyx, Ayuthaia, Thailand) with a resolution of $300 \mathrm{dpi}$.

The images on the slides were imported into Adobe Photoshop CS (v8.0; Adobe Systems Inc., San Jose, CA) and then a central area was selected, comprising $568^{2}$ pixels, situated between the buccal and lingual cortices of the mandible, and between the root apices of the molar and the mandibular canal. This area was cropped and used to quantify the trabecular area, using tools available in the same program.

The "extract" filter was then used to select just those pixels representing trabecular bone by discarding the image of medullary spaces. This procedure fills the unselected area of the image with a uniform white 

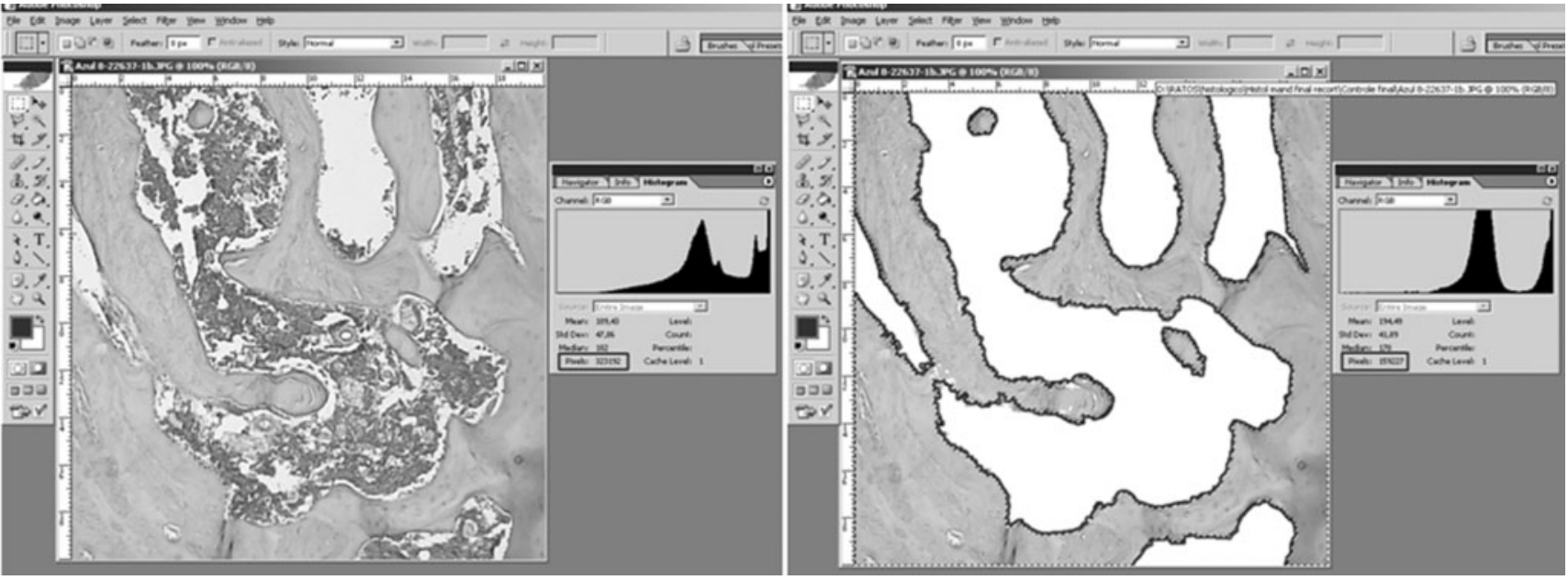

Figure 3 Cropped image and with trabecular bone selected to obtain area in pixels

colour. Next, just the coloured part of the image was selected and, once more using the histogram function, the area (in pixels) of bone trabeculae was obtained (Figure 3).

It was then possible to calculate the ratio between the total area of the image and the trabecular area. Slides were assessed in batches, with a maximum of ten images processed per day and, after a minimum interval of 7 days, a second assessment was made.

\section{Statistical analysis}

Student's $t$-test for comparing the means of paired samples was used to test the degree of agreement between the first and second measurement of trabecular bone area.

ANOVA, supplemented by Tukey's multiple comparison test, was applied at a 5\% significance level to test differences between study groups in terms of weight, optical density of subtraction images and the ratio of trabecular bone to medullary space. Since the comparisons within Group 3 were of paired data, Friedman's non-parametric test was applied to them. Data processing and analysis was performed using the statistical software SPSS v10.0 (SPSS Inc., Chicago, IL).

\section{Results}

ANOVA did not identify significant differences between the groups in terms of weight at the start of

Table 1 Comparison between first and second histological assessments (percentage of trabecular bone per field)

\begin{tabular}{lllllll}
\hline Assessment & $\mathrm{n}$ & Mean & $\begin{array}{l}\text { Standard } \\
\text { deviation }\end{array}$ & $\begin{array}{l}\text { Mean } \\
\text { difference* }\end{array}$ & $\mathrm{t}$ & $\mathrm{P}$ \\
\hline 1st & 36 & 70.32 & 14.71 & 0.57 & 1.09 & 0.28 \\
2nd & 36 & 69.74 & 16.09 & & & \\
\hline
\end{tabular}

*Mean difference between assessments the experiment; however, the same analysis supplemented by Tukey's multiple comparisons test demonstrated that Group 3 (risedronate) exhibited greater mean weight at the end of the experiment than Groups 1 (control) and 2 (corticoid) $(F=3.88 ; P=0.03)$.

Table 1 lists the data used for the error assessment of the histological method proposed as a gold standard. It is observed that the first assessment did not significantly differ from the second (Student's $t$-test for paired samples, $\alpha=1 \%$ ).

In response to this result, the mean of both assessments was used for comparisons between groups. In this comparison (Table 2), ANOVA identified statistically significant differences between all three groups. Tukey's multiple comparisons test demonstrated that Group 2 (corticoid) exhibited the lowest mean proportion of bone trabeculae per field, followed by Group 1 (control) and last, with the highest mean, Group 3 (risedronate) $(F=37.56 ; P=0.01)$.

Once the difference had been confirmed histologically, the results of radiographic subtraction were also compared (Table 3). This analysis is based on the variation in pixel intensity in the control area less that of the test area. In this case, negative figures indicate lost radiographic density, while positive numbers indicate gain. The ANOVA results show that there are significant differences between groups and Tukey's multiple comparisons test indicates that Groups 1 (control) and 3 (risedronate) do not differ and have higher means than Group 2 (corticoid).

Table 2 Histological assessment of three treatment groups: percentage of trabecular bone per field

\begin{tabular}{lllrlll}
\hline Group & $\mathrm{n}$ & Mean $^{*}$ & $\begin{array}{l}\text { Standard } \\
\text { deviation }\end{array}$ & $95 \% \mathrm{CI}^{\dagger}$ & $\mathrm{F}$ & $\mathrm{P}$ \\
\hline 1 & 12 & $72.00^{\mathrm{A}}$ & 5.95 & {$[68.22$ to 75.78$]$} & 34.03 & $<0.01$ \\
2 & 12 & $53.94^{\mathrm{B}}$ & 12.53 & {$[45.98$ to 61.90$]$} & & \\
3 & 12 & $84.14^{\mathrm{C}}$ & 7.20 & {$[79.56$ to 88.72$]$} & & \\
\hline
\end{tabular}

*Means followed by the same letter do not differ.

$95 \%$ confidence interval for mean 
Table 3 Comparison of radiographic subtraction data between groups (pixel intensity in control area minus pixel intensity in test area: negative figures indicate lost radiographic density, while positive numbers indicate gain)

\begin{tabular}{llrllll}
\hline Group & $\mathrm{n}$ & Mean $^{*}$ & $\begin{array}{l}\text { Standard } \\
\text { deviation }\end{array}$ & $95 \% C I^{\dagger}$ & $\mathrm{F}$ & $\mathrm{P}$ \\
\hline 1 & 12 & $0.34^{\mathrm{A}}$ & 0.72 & {$[-0.12$ to 0.80$]$} & $143.65<0.01$ \\
2 & 12 & $-4.28^{\mathrm{B}}$ & 1.02 & {$[-4.93$ to -3.63$]$} & \\
3 & 12 & $0.52^{\mathrm{A}}$ & 0.55 & {$[0.17$ to 0.87$]$} & & \\
\hline
\end{tabular}

*Means followed by the same letter do not differ. ${ }^{\dagger} 95 \%$ confidence interval for mean

The Group 3 (risedronate) radiographic subtraction results for the different stages of the study were then compared (Table 4). Friedman's non-parametric test indicates significant differences between them. In this group, administration of the glucocorticoid resulted in significant loss of radiographic density and the risedronate restored it.

\section{Discussion}

Osteoporosis and osteopaenia are characterized by loss of bone mass and the animal model most widely used to study them has been the rat, because loss of bone mass can be induced by a variety of mechanisms and the rat responds to the action of the drugs used to treat osteoporosis. The rat also is appropriate for research into non-invasive diagnostic techniques for later evaluation in humans. ${ }^{13}$ Furthermore, it provides fundamental data similar to those observed in the human skeleton. ${ }^{14}$

Notwithstanding, radiographic procedures designed to obtain measurements used with large animals and humans are problematic, if not impossible, due to the small size of rats. ${ }^{15}$ The first difficulty encountered is the need for a device which ensures the reproducibility of radiographic views of the same animal, immobilizing live rats during the X-ray. ${ }^{16}$ For this purpose, prior to this study the authors developed a positioning device for taking lateral X-rays of rodent mandibles, which proved to result in reproducible images. ${ }^{11}$

Still on the subject of problems with obtaining radiographs of rats, in order that these record anatomical structural details, it is necessary to use low power X-ray equipment ranging from $20-50 \mathrm{kVp} .^{15,16}$ We have previously evaluated the ideal exposure conditions for the technique being employed, ${ }^{12}$ finding that excellent quality images could be obtained using Espeed film, a focal distance of $30 \mathrm{~cm}$ and exposure time of $1 \mathrm{~s}$, with an X-ray unit operating at $8 \mathrm{~mA}$ at $50 \mathrm{kVp}$, which is the configuration used in this study.

The administration of high doses of glucocorticoids for prolonged periods is associated with loss of bone mass, which is more evident and occurs faster in trabecular bone than in cortical bone due to a more rapid turnover, a larger number of cells and a greater
Table 4 Comparison of risedronate intragroup data (pixel intensity in control area minus pixel intensity in test area: negative figures indicate lost radiographic density, while positive numbers indicate gain)

\begin{tabular}{llrlll}
\hline Measure* $^{*}$ & $\mathrm{n}$ & Mean & $\begin{array}{l}\text { Standard } \\
\text { deviation }\end{array}$ & Mean rank & $\mathrm{P}$ \\
\hline I vs $\mathrm{C}$ & 12 & -4.76 & 0.73 & $1.00^{\mathrm{A}}$ & $<0.01$ \\
I vs $\mathrm{R}$ & 12 & 0.52 & 0.55 & $2.00^{\mathrm{B}}$ & \\
C vs $\mathrm{R}$ & 12 & 5.81 & 1.22 & $3.00^{\mathrm{C}}$ & \\
\hline
\end{tabular}

*I, initial; $\mathrm{C}$, after administration of corticoid; $\mathrm{R}$, after administration of risedronate. ${ }^{\dagger}$ Mean ranks followed by the same letter do not differ

surface area. ${ }^{17-21}$ The glucocorticoid dosage used in this study has previously been employed by Takahashi et $\mathrm{al}^{5}$ to induce osteopaenia in female rats. Bone mass was reduced on average by $6 \%$ in relation to controls, verified by bone densitometry of the second lumbar vertebra. The lower trabecular volume observed in Group 2 (corticoid) in this study has also been observed in other studies. ${ }^{20,22}$

In spite of a raised awareness of the potential risk of osteonecrosis of the jaw among patients receiving bisphosphonate therapy, ${ }^{23}$ this is still the treatment of choice for glucocorticoid-induced osteoporosis and is considered the gold standard of pharmacological treatment. ${ }^{5,18,20}$ Administered orally, bisphosphonates are considered effective for both prevention and treatment, since they reduce bone loss and increase bone mineral density of the vertebrae and femur by 4.5 $75 \%{ }^{1}$ Of the bisphosphonates, it is risedronate sodium that has the most powerful action, offers the best tolerance when given orally and has least side effects, in addition to having a strong affinity for bone tissue and a strong antiresorption potential, with a dose-dependent effect. ${ }^{5,24-27}$

In this study, treatment with bisphosphonate was capable of restoring the lost bone mass caused by administration of the glucocorticoid, raising the trabecular bone/medullary spaces ratio to levels slightly above those of the control group, which has also been observed in other studies. ${ }^{5,20}$

Diagnosis and study of metabolic diseases of bone, especially of its trabecular portion, involves histomorphometry or quantitative histology, which consists of counting or measuring the cellular components and changes in bone microarchitecture. The method permits mineralization to be measured and bone formation to be studied which, in the case of glucocorticoid-induced osteoporosis, is characterized by thinning of trabeculae, which leads to a reduction in bone volume, after high doses, and to recovery of bone mass after treatment with bisphosphonate. ${ }^{28,29}$ Trabecular organization parameters may be associated with bone mineral density. When performing microscopic analysis of trabecular density, it is usual to superimpose a counting grid on the image in order to measure trabecular and medullary areas. Counting the number of points intersecting the histological image of the area of interest allows it to be quantified for later calculation of 
proportions. ${ }^{30,31}$ In this study, measuring the area of trabeculae in each field with the aid of an image analysis program proved to be simple and reproducible, demonstrating that this method can serve as a model for histomorphometric studies.

Many different methods have been employed to measure bone mineral density when diagnosing osteoporosis: quantitative computed tomography, peripheral quantitative computed tomography and microtomography, ${ }^{7,8,10,32-36}$ but it is dual-energy X-ray absorptiometry (DXA) that is used as the gold standard in studies of bone mineral density. ${ }^{37}$

Comparison of conventional radiographs offers little precision and merely provides evidence of accentuated changes in bone density. ${ }^{38,39}$ Detection of subtle changes in the density of mineralized tissues has been facilitated by subtraction radiography, when compared with a subjective interpretation of a pair of radiographs; ${ }^{40,41}$ however, no studies were found in the literature that have evaluated osteoporosis-related bone alterations in rats using this method.

When performing subtraction radiography, geometric variations and variations in density of the radiographic film resulting from exposure and processing conditions must be minimized to make it possible

\section{References}

1. Hosking DJ, Geusens P, Prizzoli R. Osteoporosis therapy: an example of putting evidence-based medicine into clinical practice. Q J Med 2005; 98: 403-413.

2. Birkenfeld L, Yemini M, Kase NG, Birkenfeld A. Menopauserelated oral alveolar bone resorption: a review of relatively unexplored consequences of estrogen deficiency. Menopause 1999; 6: $129-133$

3. Turner AS. Animal models of osteoporosis - necessity and limitations. Eur Cell Mater 2001; 22: 66-81.

4. Devogelaer JP, Goemaere S, Boonen S, Body JJ, Kaufman JM, Reginster JY, et al. Evidence-based guidelines for the prevention and treatment of glucocorticoid-induced osteoporosis: a consensus document of the Belgian Bone Club. Osteoporos Int 2006; 17: $8-19$.

5. Takahashi K, Fukushima S, Nozaki K, Kokubo S, Teramura K, Miyata K. Effect of incadronate on corticosteroid-induced osteopenia in rats. Yakugaku Zasshi 2004; 124: 627-630.

6. Sakakura Y, Shide N, Tsuruga E, Irie K, Yajima T. Effects of running exercise on the mandible and tibia of ovariectomized rats. $J$ Bone Miner Metab 2001; 19: 159-167.

7. Jiang G, Matsumoto H, Fujii A. Mandible bone loss in osteoporosis rats. J Bone Miner Metab 2003; 21: 388-395.

8. Kuroda S, Mukohyama H, Kondo H, Aoki K, Ohya K, Ohyama $\mathrm{T}$, et al. Bone mineral density of the mandible in ovariectomized rats: analyses using dual energy X-ray absorptiometry and peripheral quantitative computed tomography. Oral Dis 2003; 9: $24-28$

9. Hidaka S, Okamoto Y, Miyazaki K, Uesugi T. Evaluation of a soybean product fujiflavone p40 as an antiosteoporotic agent in rats. Phytother Res 2003; 17: 112-119.

10. Yang J, Pham SM, Crabbe DL. Effects of oestrogen deficiency on rat mandibular and tibial microarchitecture. Dentomaxillofac Radiol 2003; 32: 247-251.

11. Fontanella V, Mahl CRW, Travessas J, Padilha DMP. Evaluation of an apparatus for standardized radiographs of the rat mandible. In: Reports from the 15th International Congress of Dentomaxillofacial Radiology. Medimond: Bologna, 2005, pp 1114. to obtain a quantitative analysis of longitudinal bone alterations in mineralized tissues. ${ }^{42}$

In this study, even though the X-rays had been standardized, discrepancies were observed in the size of images, attributed to growth of the animals. In order to overcome this situation, the first image was adjusted to the second, using an open access program, Regeemy, available at http://regima.dpi.inpe.br, that had originally been designed to align satellite image and has already been tested with X-ray images. ${ }^{43}$

A study that compared five software programs' efficacy for radiographic subtraction considered that Adobe Photoshop generated subtraction images of the lowest quality. ${ }^{44}$ However, bearing in mind that the authors did not describe the steps they took to perform subtraction, we believe, based on analysis of the image published, that they merely applied transparency to the upper layer of the image without inverting its greyscale. In this study, the subtraction images generated were considered completely satisfactory.

In conclusion, administration of methylprednisolone was capable of inducing osteoporosis in the mandibles of female rats and the lost bone mass was restored by administration of risedronate sodium. These changes were detected by means of subtraction radiography.

12. Mahl CRW, Fontanella V. Optimal parameters for lateral oblique radiographs of rat mandibles. Dentomaxillofac Radiol 2008; 37: 224-227.

13. Thorndike EA, Turner AS. In search of an animal model for postmenopausal diseases. Front Biosci 1998; 3: c17-c26.

14. Aerssens J, Boonen S, Lowet G, Dequeker J. Interspecies differences in bone composition, density, and quality: potential implications for in vivo bone research. Endocrinology 1998; 139: 663-670.

15. Gaegauf-Zollinger R, Burckhardt JJ, Guggenheim B. Radiographic measurements of alveolar bone loss in the rat. Arch Oral Biol 1982; 27: 651-658.

16. Raymond F, Cimasoni G. Radiographic measurements of alveolar bone loss in the living rat. J Periodontol 1997; 68: 141-144.

17. Canalis E, Giustina A. Glucocorticoid-induced osteoporosis: summary of a workshop. J Clin Endocrinol Metab 2001; 86: 5681-5685.

18. Boling EP. Secondary osteoporosis: underlying disease and the risk for glucocorticoid-induced osteoporosis. Clin Ther 2004; 26: $1-14$.

19. Cooper MS. Sensitivity of bone to glucocorticoids. Clinical Science 2004; 107: 111-123.

20. Iwamoto J, Seki T, Takeda T, Sato Y, Yamada H, Shen C-L, et al. Preventive effects of risedronate and calcitriol on cancellous osteopenia in rats treated with high-dose glucocorticoid. Exp Anim 2006; 55: 349-355.

21. Mazziotti G, Angeli A, Bilezikian JP, Canalis E, Giustina A. Glucocorticoid-induced osteoporosis: an update. Trends Endocrinol Metab 2006; 17: 144-149.

22. Kimura E, Nishioka T, Hasegawa K, Maki K. Effects of bisphosphonate on the mandible of rats in the growing phase with steroid-induced osteoporosis Oral Dis (OnlineEarly Articles) 2007. doi:10.1111/j.1601-0825.2006.01331.x

23. Ruggiero S, Gralow J, Marx RE, Hoff AO, Schubert MM, Huryn $\mathrm{JM}$, et al. Practical guidelines for the prevention, diagnosis, and treatment of osteonecrosis of the jaw in patients with cancer. $J$ Oncol Practice 2006; 2: 7-14. 
24. Garton M J. Treatment of osteoporosis with bisphosphonates. CPD Rheumatol 2001; 2: 64-70.

25. McClung M, Geusens P. Review of risedronate in the treatment of osteoporosis. Expert Opin Pharmacother 2001; 2: 2011-2025.

26. Iwaniec UT, Samnegård E, Cullen DM, Kimmel DB. Maintenance of cancellous bone in ovariectomized, human parathyroid hormone [hPTH(1-84)]-treated rats by estrogen, risedronate, or reduced hPTH. Bone 2001; 29: 352-360.

27. Jutea S, Orbai P, Ghervan C, Duncea I, Gozariu L. Glucocorticoids increase inflammation-mediated osteopenia in the rat. Acta Endocrinol (Bucharest) 2006; 2: 11-18.

28. Huang TS, Yang RS, Tsai TW, Liu SH. Growth hormone cannot enhance the recovery of dexamethasone-induced osteopenia after withdrawal in young female Wistar rats. Tohoku J Exp Med 2004; 204: $257-266$

29. Dalle Carbonare L, Bertoldo F, Valenti MT, Zenari S, Zanatta $\mathrm{M}$, Sella $\mathrm{S}$, et al. Histomorphometric analysis of glucocorticoidinduced osteoporosis. Micron 2005; 36: 645-652.

30. Piai CR, Carvalho VAP, Werkman C, Anbinder AL, Rocha RF. Efeitos do risedronato na reparação óssea de ratos machos e fêmeas com osteopenia. Cienc Odontol Bras 2005; 8: 77-82.

31. Pinto AS, Oliveira TT, Del Carlo RJ, Nagem TJ, Fonseca CC, Moraes GHK, et al. Efeitos de tratamento combinado de alendronato de sódio, atorvastatina cálcica e ipriflavona na osteoporose induzida com dexametasona em ratas. Rev Bras Cienc Farmaceuticas/Braz J Pharm Sci 2006; 42: 99-107.

32. Petrikowski CG, Overton TR. Quantitative radiographic changes in the mandible, femur and vertebra in lactating rats fed a lowcalcium diet. Dentomaxillofac Radiol 1996; 25: 136-145.

33. Glatt M. The bisphosphonate zoledronate prevents vertebral bone loss in mature estrogen-deficient rats as assessed by microcomputed tomography. Eur Cell Mat 2001; 10: 18-26.

34. Rahnama M. Experimental investigations on bone density of the mandible and spine in ovariectomized rats. Bull Vet Inst Pulawy 2003; 47: 225-230.
35. Kamitani Y, Maki K, Tofani I, Nishikawa Y, Tsukamoto K, Kimura M. Effects of grape seed proanthocyanidins extract on mandibles in developing rats. Oral Dis 2004; 10: 27-31.

36. Cho MH, Chun IK, Lee SC, Cho MH, Lee SY. Trabecular thickness measurement in cancellous bones: postmortem rat studies with the zoom-in micro-tomography technique. Physiol Meas 2005; 26: 667-676.

37. World Health Organization. Assessment of fracture risk and its application to screening for postmenopausal osteoporosis: report of a WHO Study Group. Geneva: World Health Organization, 1994.

38. Moriya Y, Ito K, Murai S. Effects of experimental osteoporosis on alveolar bone loss in rats. J Oral Sci 1998; 40: 171-175.

39. Maki K, Nishida I, Kimura M. The effects of oral ipriflavone on the rat mandible during growth. Eur J Orthod 2005; 27: 27-31.

40. Bittar-Cortez JA, Passeri LA, Boscolo FN, Haiter-Neto F. Comparison of hard tissue density changes around implants assessed in digitized conventional radiographs and subtraction images. Clin Oral Implants Res 2006; 17: 560-564.

41. Sakakura CE, Marcantonio E Jr, Wenzel A, Scaf G. Influence of cyclosporin A on quality of bone around integrated dental implants: a radiographic study in rabbits. Clin Oral Implants Res 2007; 18: 34-39.

42. Southard TE, Wunderle DM, Southard KA, Jakobsen JR. Geometric and densitometric standardization of intraoral radiography through use of a modified XCP system. Oral Surg Oral Med Oral Pathol Oral Radiol Endod 1999; 87: 253-257.

43. Dotto GN. Registro de radiografias periapicais para a técnica de subtração [doctoral dissertation]. São José dos Campos, Brazil: Universidade Estadual Paulista Tese de Doutorado, Faculdade de Odontologia, 2005.

44. Güneri P, Goğü S, Tuğsel Z, Ozturk A, Gungor C, Boyacioğlu H. Clinical efficacy of a new software developed for dental digital subtraction radiography. Dentomaxillofac Radiol 2006; 35: $417-421$. 